\title{
Glass Transition Temperature, Free Volume, and Curing Kinetics of Unsaturated Polyester
}

\author{
S. C. MA, H. L. LIN, and T. L. YU* \\ Department of Chemical Engineering, Yuan-Ze Institute of Technology, \\ Nei-Li, Taoyuan, Taiwan, 32026
}

(Received June 1, 1992)

\begin{abstract}
Variations of glass transition temperature and free volume during the period of curing reaction for unsaturated polyester were calculated respectively from a theoretical equation developed in this work and Shimha-Boyer's free volume equation. The calculated free volume was applied to Huang \& Lee's curing kinetic model to predict DSC curing reaction data of unsaturated polyester. Good agreement between the prediction and experimental results was found.
\end{abstract}

KEY WORDS Unsaturated Polyester / Glass Transition Temperature / Free Volume / Curing Kinetics /

Unsaturated polyester is one of the major resins of polymer composites. However, a theoretical discussion of the glass transition temperature of the crosslinked unsaturated polyester has not yet appeared. In most applications, it is often cured with styrene monomer as a crosslinking agent. In some cases, one may obtain unreacted residual styrene monomer and unreacted ester double bonds in the cured polymer network. The residual styrene monomer acts as a diluent in the system. It is well known that the curing reaction of unsaturated polyester resin is strongly controlled by the diffusion of the polymeric radical from the beginning of the reaction. ${ }^{1}$ Hence, the reaction may be controlled by the free volume in the system. In the present paper, we are interested in: (1) the relation of $T_{\mathrm{g}}$ of the crosslinked unsaturated polyester to the crosslinked density, reacted styrene monomer and residual unreacted styrene monomer content; (2) variation of free volume during the period of curing reaction of unsaturated polyester; and (3) applications of

* To whom correspondence should be addressed. the free volume to the curing kinetics of unsaturated polyesters.

\section{THEORY OF $T_{\mathrm{g}}$ OF CROSSLINKED UNSATURATED POLYESTER}

The unsaturated polyester resin is a condensation polymer of diol, dibasic acid and unsaturated dibasic acid, and the copolymer is crosslinked with styrene monomer. We may assume that the crosslinked network is a copolymer of ester and styrene. For a linear copolymer of ester and styrene, the glass transition temperature of the copolymer has the following relation with its composition. ${ }^{2}$

$$
\frac{1}{T_{\mathrm{g}, 1}}=\frac{W_{\mathrm{PE}}}{T_{\mathrm{gPE}}^{\infty}}+\frac{W_{\mathrm{PS}}}{T_{\mathrm{gPS}}^{\infty}}
$$

where $W_{\mathrm{PE}}$ is the weight fraction of polyester in the crosslinked polymer network, $W_{\mathrm{PS}}$ the weight fraction of polystyrene in the crosslinked polymer network, $W_{\mathrm{PE}}+W_{\mathrm{PS}}=1, T_{\mathrm{gPE}}^{\infty}$ the glass transition temperature of polyester with an infinite molecular weight, $T_{\mathrm{gPS}}^{\infty}$ the glass 
transition temperature of polystyrene with an infinite molecular weight, $T_{\mathrm{gPS}}^{\infty}=373 \mathrm{~K},{ }^{3} T_{\mathrm{g}, 1}$ the glass transition temperature of the uncrosslinked linear copolymer of ester and styrene.

The introduction of crosslinks restricts the mobility of polymer segments; hence the glass transition temperature increases. The influence of crosslink on the glass transition, as cited by Nielson, ${ }^{4}$ was developed by DiBenedetto ${ }^{5}$ and given by:

$$
T_{\mathrm{g}, \mathrm{C}}=T_{\mathrm{g}, 1}\left(1+K_{2} \frac{X_{\mathrm{C}}}{1-X_{\mathrm{C}}}\right)
$$

where $T_{\mathrm{g}, \mathrm{C}}$ is the glass transition temperature of the crosslinked polymer, $T_{\mathrm{g}, 1}$ the glass transition temperature of the uncrosslinked linear polymer as a reference, $K_{2}$ a constant and $X_{\mathrm{C}}$ the crosslink density expressed as the mole ratio of monomer units present as crosslinks to the total monomer units present in the polymer network.

Owing to impurity, moisture, or the lower curing temperature etc., one may obtain unreacted residual styrene monomer and unreacted ester double bonds in the cured polymer network. The unreacted residual styrene monomer acts as a diluent in the polymer network; hence the glass transition temperature decreases. In the present system, the glass transition temperature of the crosslinked unsaturated polyester with unreacted residual styrene monomer can be expressed by ${ }^{6}$ :

$$
\begin{aligned}
T_{\mathrm{g}}= & \left(\frac{T_{\mathrm{gPS}}^{\infty} T_{\mathrm{gPE}}^{\infty}}{T_{\mathrm{gPS}}^{\infty} W_{\mathrm{PE}}+T_{\mathrm{gPE}}^{\infty} W_{\mathrm{PS}}}\right)\left(1+K_{2} \frac{X_{\mathrm{C}}}{1-X_{\mathrm{C}}}\right) \\
& \times W_{\mathrm{P}}+T_{\mathrm{g}, \mathrm{S}} W_{\mathrm{S}}
\end{aligned}
$$

where $T_{\mathrm{g}, \mathrm{s}}$ is the glass transition temperature of the styrene monomer, $T_{\mathrm{g}, \mathrm{S}}=135 \mathrm{~K},{ }^{2} W_{\mathrm{S}}$ the weight fraction of the unreacted residual styrene monomer, and $W_{\mathrm{P}}$ the weight faction of the polymer network $W_{\mathrm{P}}+W_{\mathrm{S}}=1, K_{2}$ a constant. Since the molecular weight of the unsaturated polyester in this system is about
1800 , we were not able to get an experimental value of $T_{\mathrm{gPE}}^{\infty} \cdot K_{2}$ and $T_{\mathrm{gPE}}^{\infty}$ are parameters obtained by fitting the experimental data to eq 3 as will be shown latter.

\section{FREE VOLUME FRACTION}

The free volume fraction $V_{\mathrm{f}}$ is approximate to increase linearly with temperature in accordance with the following relations ${ }^{3}$ :

$$
\begin{aligned}
& V_{\mathrm{f}}=V_{\mathrm{fg}}+\beta_{1}\left(T-T_{\mathrm{g}}\right) \\
& \quad \text { for curing temperature } T>T_{\mathrm{g}} \\
& V_{\mathrm{f}}=V_{\mathrm{fg}}+\beta_{\mathrm{g}}\left(T-T_{\mathrm{g}}\right) \\
& \quad \text { for curing temperature } T<T_{\mathrm{g}}
\end{aligned}
$$

where $V_{\mathrm{f}}$ is the volume fraction of free volume at temperature $T, V_{\mathrm{fg}}=0.025$ the volume fraction of free volume at $T_{\mathrm{g}}, \beta_{1}$ the thermal expansion coefficient at liquid state, $\beta_{\mathrm{g}}$ the thermal expansion coefficient at glassy state, and $\Delta \beta=\beta_{1}-\beta_{\mathrm{g}}$. According to Simha-Boyer, $\Delta \beta$ and $\beta_{1}$ have the following relations with $T_{\mathrm{g}}$ for many polymers ${ }^{7}$ :

$$
\begin{aligned}
& \beta_{1} T_{\mathrm{g}}=0.164 \\
& \Delta \beta T_{\mathrm{g}}=0.113
\end{aligned}
$$

In this work, we use eq 4 and 5 to calculate variation of free volume fraction from $T_{\mathrm{g}}$ during the curing reaction of unsaturated polyester.

\section{CURING MODEL OF UNSATURATED POLYESTER}

In most studies on curing reactions of unsaturated polyester, researchers ${ }^{8-11}$ have used empirical models to fit the reaction profiles.

A typical model is

$$
\frac{\mathrm{d} \alpha}{\mathrm{d} t}=\left(K_{1}+K_{2} \alpha^{\mathrm{m}}\right)(1-\alpha)^{n}
$$

Where $\alpha$ is the conversion and is defined by the following equation: 


$$
\alpha=\frac{\left(\begin{array}{c}
\text { total number of double } \\
\text { bonds which has been reacted }
\end{array}\right)}{\left(\begin{array}{c}
\text { total number of double bonds } \\
\text { initially presented in the system }
\end{array}\right)}
$$

The above model fits the experimental results well but has little physical meaning.

The other kinetic model is based on the free radical polymerization mechanism. Several authors have proposed methods of incorporating diffusion resistance into free radical reaction kinetics, and have advanced mechanistic interpretations based on the concepts of molecular entanglement, ${ }^{12-14}$ free volume and the glass transition. ${ }^{15}$ Chiu et al. ${ }^{16}$ and Huang et al. ${ }^{17}$ used film theory in which the diffusion and reaction resistances are combined in series.

By assuming (1) no monomer reacts untill the number of initiator radical created is equal to the effective number of inhibitor molecule initially presented (this assumption is valid because that the reaction between the initiator and inhibitor is much faster than the reaction between the initiator and the monomer $)^{18,19}$; (2) termination is predominated by combination; (3) homopolymerization of unsaturated polyester is negligible; (4) copolymerization of styrene and unsaturated polyester can be expressed by a single average reaction rate constant; (5) termination is totally diffusion controlled; and (6) quasi steady state reaction, Huang et al. derived the following curing kinetic model for unsaturated polyester resin ${ }^{17}$ :

$$
\frac{\mathrm{d} \alpha}{\mathrm{d} t}=\frac{1-\alpha}{1 / 2 \pi_{2} \pi_{3}+\pi_{4}}
$$

In eq $7, \pi_{2}$ is the parameter related to the diffusion effect on termination; $\pi_{3}$ the parameter related to the kinetic effect on propagation; and $\pi_{4}$ the parameter related to the diffusion effect on propagation.

$\pi_{2}, \pi_{3}$, and $\pi_{4}$ can be defined by the following equations:

$$
\begin{gathered}
\pi_{2}=\frac{A_{\mathrm{p}}}{F} \exp \left(\frac{B_{\mathrm{p}}}{V_{\mathrm{f}}}\right) \\
\pi_{3}=F f I_{0} k_{\mathrm{d}} k_{\mathrm{p} 0} \exp \left(-\int_{t_{\mathrm{z}}}^{t} k_{\mathrm{d}} \mathrm{d} t\right) \\
\pi_{4}=A_{\mathrm{M}} \exp \left(\frac{B_{\mathrm{M}}}{V_{\mathrm{f}}}\right)
\end{gathered}
$$

where $F$ is a parameter defined as:

$$
\begin{aligned}
F & =\frac{\left(\begin{array}{c}
\text { free radical concentration assuming that the } \\
\text { termination is totally diffusion controlled }
\end{array}\right)}{\left(\begin{array}{c}
\text { free radical concentration assuming } \\
\text { no termination }
\end{array}\right)} \\
& =\frac{k_{\mathrm{d}} A_{\mathrm{p}} \exp \left(B_{\mathrm{p}} / V_{\mathrm{f}}\right)}{\exp \left[k_{\mathrm{d}}\left(t-t_{z}\right)\right]-1}
\end{aligned}
$$

and $I_{0}$ is the initial initiator concentration; $f$ the initiator efficiency; $t_{\mathrm{Z}}$ the induction time for the initiator to consume the inhibitor; $k_{\mathrm{d}}, k_{\mathrm{i}}$, $k_{\mathrm{z}}, k_{\mathrm{p}}$, and $k_{\mathrm{t}}$ the rate constants of initiator decomposition, primary radical formation, inhibition, propagation, and termination respectively for the overall reaction; $k_{\mathrm{p} 0}$ and $k_{\mathrm{t} 0}$ the rate constants of propagation and termination respectively on the surface of radical centers.

\section{EXPERIMENTAL}

\section{Unsaturated Polyester}

Unsaturated polyester was polymerized from isophthalic acid (IPA), fumaric acid (FA), and propylene glycol (PG) by the usual condensation method. The mole ratio of the final composition of the polyester resin determined by NMR was IPA/FA/PG $=1 / 1.64 / 3.23$. Thus, the final unsaturated polyester has the following specifications: acid value about $28 \mathrm{mg}$ $\mathrm{KOH} / \mathrm{g}, M_{n}=1800 \mathrm{~g} \mathrm{~mol}^{-1}$ and $M_{w} / M_{n}=4.3$. The resin with a styrene/polyester weight ratio of $33 / 67$ was used for DSC and FTIR curing reactions. 


\section{Initiator}

The peroxide was tert-butyl peroxybenzoate from Akzo Chemie Co. with a purity of $98 \%$ and an active oxygen content of $8.0 \%$. In this study, $1 \%$ by weight of initiator was added into the resin.

\section{Differential Scanning Calorimetry (DSC)}

A Du Pont 910 DSC was used to measure the exothermic reaction of curing. Hermetic DSC pans were used to minimize loss of volatile materials (such as styrene monomer) during the heating of the sample in the DSC cell. The weight of the sample used ranges from $4 \mathrm{mg}$ to $6 \mathrm{mg}$. A small sample size was required in order to achieve isothermal operating during cure.

\section{Fourier Transform Infrared Spectroscopy (FTIR)}

A Perkin-Elmer FTIR 1745X was used to measure the concentration of the unreacted $\mathrm{C}=\mathrm{C}$ bond and styrene $\mathrm{C}=\mathrm{C}$ bond in the curing system. Absorptions at $\lambda_{\max }^{-1}=982 \mathrm{~cm}^{-1}$ of ester $\mathrm{C}=\mathrm{C}$ bond and $\lambda_{\max }^{-1}=912 \mathrm{~cm}^{-1}$ of styrene $\mathrm{C}=\mathrm{C}$ bond were used to determine the unreacted ester $\mathrm{C}=\mathrm{C}$ bond and residual styrene monomer content respectively. The absorption peak at $\lambda_{\max }^{-1}=1750 \mathrm{~cm}^{-1}$ of $\mathrm{C}=\mathrm{O}$ was taken as an internal standard.

\section{TMA Glass Transition Temperature Measure- ments}

The glass transition temperature was measured by Thermal Mechanical Analysis (TMA Du Pont 945) with a heating rate of $10^{\circ} \mathrm{C}$ $\min ^{-1}$. The sample size for TMA measurement is $4 \mathrm{~mm} \times 4 \mathrm{~mm} \times 3 \mathrm{~mm}$.

\section{RESULTS AND DISCUSSION}

Glass Transition Temperature and Free Volume

\section{Fraction}

To determine parameters $T_{\mathrm{gPE}}^{\infty}$ and $K_{2}$ of eq 3 , unsaturated polyester resins with initial styrene monomer content from $12.0 \%$ to $50.0 \%$ were prepared and cured isothermally

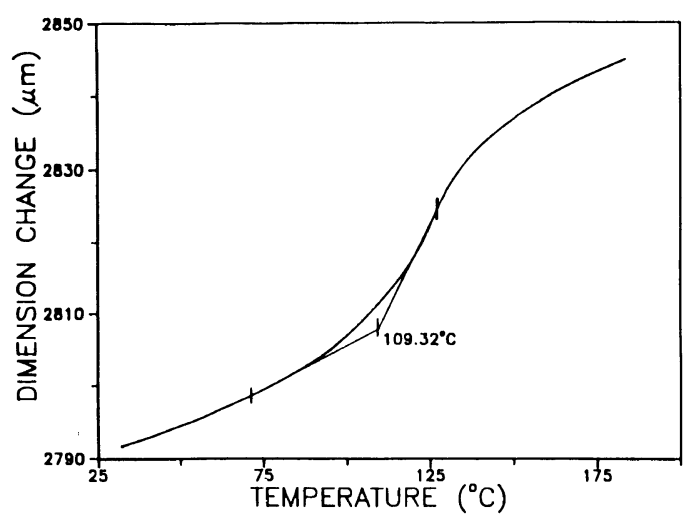

Figure 1. TMA curve of the unsaturated polyester with $30 \%$ styrene monomer cured under $100^{\circ} \mathrm{C}$ for 2 hours.

at $100^{\circ} \mathrm{C}$ for 2 hours. The glass transition temperature of the partially cured unsaturated polyester could not be measured by DSC because of additional cure reactions that are the immediate results of reacting at the glass transition. Thermal mechanical analysis (TMA) was used to determine the glass transition in this work. Figure 1 is the TMA curve of unsaturated polyester with $30 \%$ styrene monomer cured at $100^{\circ} \mathrm{C}$ for two hours. The crosslinked density, $X_{\mathrm{C}}$, residual unreacted styrene monomer content, $W_{\mathrm{S}}$, were determined by Fourier Transform Infra Red Spectroscopy (FTIR).

In eq 3 , we have two variables $W_{\mathrm{PS}}$ and $X_{\mathrm{C}}$ and two unknown parameters $K_{2}$ and $T_{\mathrm{gPE}}^{\infty}$ to be estimated. The parameters $T_{\mathrm{gPE}}^{\infty}$ and $K_{2}$ obtained from a least squares fit of our experimental data to eq 3 are $313 \mathrm{~K} \quad 1.21$ respectively. The value of $T_{\mathrm{gPE}}^{\infty}=313 \mathrm{~K}$ is consistent with that predicted from the chemical structure of unsaturated polyester using the van Krevelen and Hoftyzer theory. ${ }^{6,20}$ The value of $K_{2}=1.21$ is consistent with that of the styrene/divinylbenzene system which was estimated by DiBenedetto. ${ }^{5,6}$

By rearranging eq 3 , we obtain eq 12 :

$$
\left(\frac{T_{\mathrm{g}}-T_{\mathrm{g}, \mathrm{S}} W_{\mathrm{S}}}{W_{\mathrm{P}}}\right)\left(\frac{T_{\mathrm{gPS}}^{\infty}\left(1-W_{\mathrm{PS}}\right)+T_{\mathrm{gPE}}^{\infty} W_{\mathrm{PS}}}{T_{\mathrm{gPS}}^{\infty} T_{\mathrm{gPE}}^{\infty}}\right)
$$




$$
=1+K_{2} \frac{X_{\mathrm{C}}}{1-X_{\mathrm{C}}}
$$

By substituting $T_{\mathrm{gPE}}^{\infty}=313 \mathrm{~K}$ into eq 12 , and plotting the left hand side of eq $12 v s$. $X_{\mathrm{C}} /\left(1-X_{\mathrm{C}}\right)$ the slope is $K_{2}$. The plot of eq 12 is shown in Figure 2.

By rearranging eq 3 , we obtain eq 13 :

$$
\begin{gathered}
\left(\frac{W_{\mathrm{p}}}{T_{\mathrm{g}}-T_{\mathrm{g}, \mathrm{S}} W_{\mathrm{S}}}\right)\left(1+K_{2} \frac{X_{\mathrm{C}}}{1-X_{\mathrm{C}}}\right) \\
=\frac{1}{T_{\mathrm{gPE}}^{\infty}}+\left(\frac{1}{T_{\mathrm{gPS}}^{\infty}}-\frac{1}{T_{\mathrm{gPE}}^{\infty}}\right) W_{\mathrm{PS}}
\end{gathered}
$$

By substituting $K_{2}=1.21$ into eq 13 , and

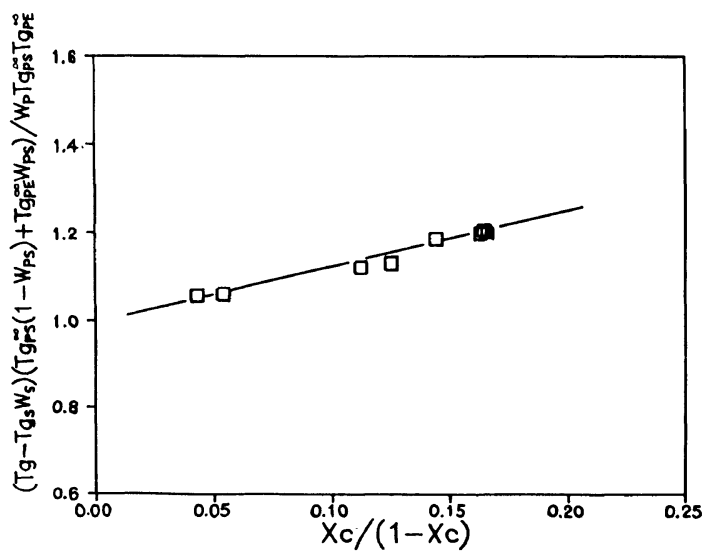

Figure 2. Plot of eq 12. ( $\square$ ), experimental data; (-), theoretical curve.

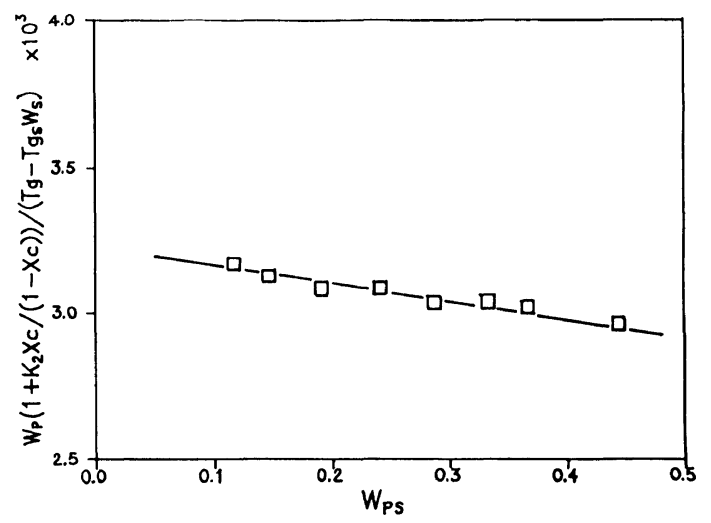

Figure 3. Plot of eq 13. ( $\square$ ), experimental data; (-), theoretical curve. plotting the left hand side of eq $13 v s . W_{\mathrm{PS}}$ the intercept is $1 / T_{\mathrm{gPE}}^{\infty}$. The plot of eq 13 is shown in Figure 3.

Table I shows experimental data of $T_{\mathrm{g}}, X_{\mathrm{C}}$, and $W_{\mathrm{S}}$ of the cured resin and corresponding $T_{\mathrm{g}}$ predicted from eq 3 . The first column in Table I is the initial total styrene content of the uncured resin.

Figures 4 and 5 show FTIR absorption spectra of styrene vinyl at $912 \mathrm{~cm}^{-1}$ and ester vinyl at $982 \mathrm{~cm}^{-1}$ respectively of the unsaturated polyester resin with a styrene content of $33.0 \%$ with various curing time with the curing temperature being $110^{\circ} \mathrm{C}$. The conversion, $\alpha$, residual styrene monomer, $W_{\mathrm{S}}$, and crosslinked density, $X_{\mathrm{C}}$, at each curing time are listed in Table II. The corresponding $T_{\mathrm{g}}$ were calculated from eq 3 using $K_{2}=1.21$ and $T_{\mathrm{gPE}}^{\infty}=313 \mathrm{~K}$. The variation of free volume $V_{\mathrm{f}}$ $v s$. reaction time was calculated from glass transition temperature using eq 4 and 5 . The glass transition temperature and the free volume fraction $V_{\mathrm{f}}$ at each curing time stage are also listed in Table II.

The relation between the $T_{\mathrm{g}}$ and conversion $\alpha$ can be described by the following equation:

$$
T_{\mathrm{g}}=K_{1} \exp \left(K_{3} \alpha\right)
$$

$T_{\mathrm{g}}$ data listed in Table II $v s$. conversion $\alpha$ together with the curve fitted to eq 14 are plotted in Figure 6. $K_{1}$ and $K_{3}$ of eq 14 obtained from least squares fit of these data to eq 14 are 252.0 and 0.54 , respectively.

Table I. Properties of unsaturated polyester isothermal cured at $100^{\circ} \mathrm{C}$ for 2 hours

\begin{tabular}{cclcc}
\hline $\begin{array}{c}\text { Sample } \\
\text { (Styrene \%) }\end{array}$ & $X_{\mathrm{C}}$ & \multicolumn{1}{c}{$W_{\mathrm{S}}$} & $\begin{array}{c}T_{\mathrm{g}} / \mathrm{K} \\
\text { (Expt.) }\end{array}$ & $\begin{array}{c}T_{\mathrm{g}} / \mathrm{K} \\
\text { (Theory) }\end{array}$ \\
\hline 12.0 & 0.0514 & 0.00368 & 335.2 & 336.2 \\
15.0 & 0.0409 & 0.00424 & 335.3 & 333.5 \\
20.0 & 0.1008 & 0.00992 & 355.9 & 361.6 \\
25.0 & 0.1114 & 0.0125 & 360.0 & 369.2 \\
30.0 & 0.1260 & 0.0184 & 382.3 & 378.1 \\
35.0 & 0.1422 & 0.0265 & 388.3 & 387.5 \\
40.0 & 0.1403 & 0.0545 & 382.4 & 381.5 \\
50.0 & 0.1413 & 0.1018 & 377.3 & 374.7
\end{tabular}




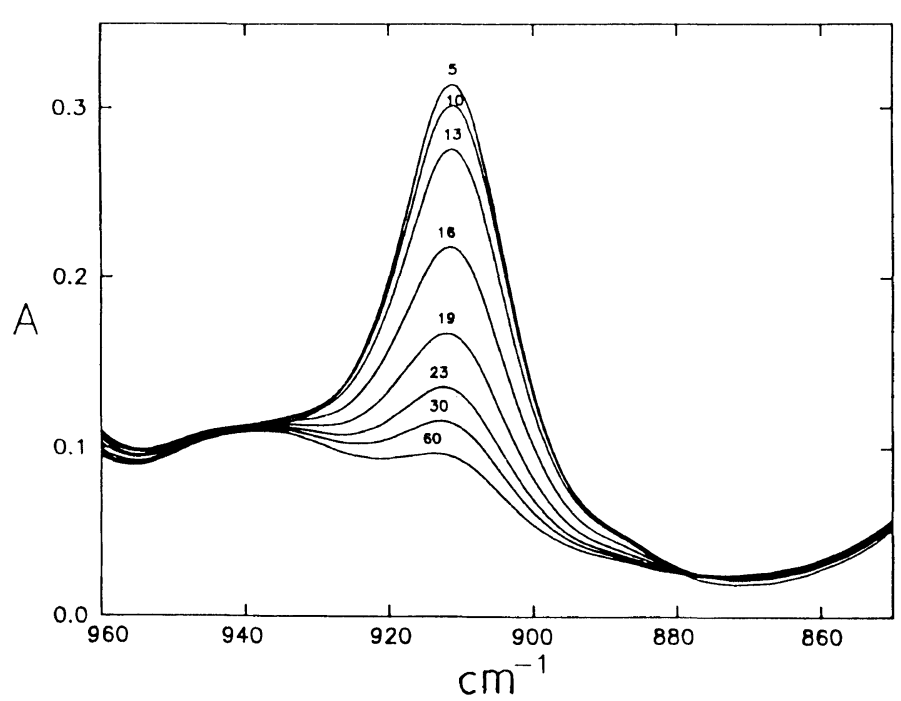

Figure 4. FTIR absorption spectra at $912 \mathrm{~cm}^{-1}$ of the unsaturated polyester with a styrene content of $33 \%$ cured at a temperature of $110^{\circ} \mathrm{C}$. The numeric values in the graph is the curing time.

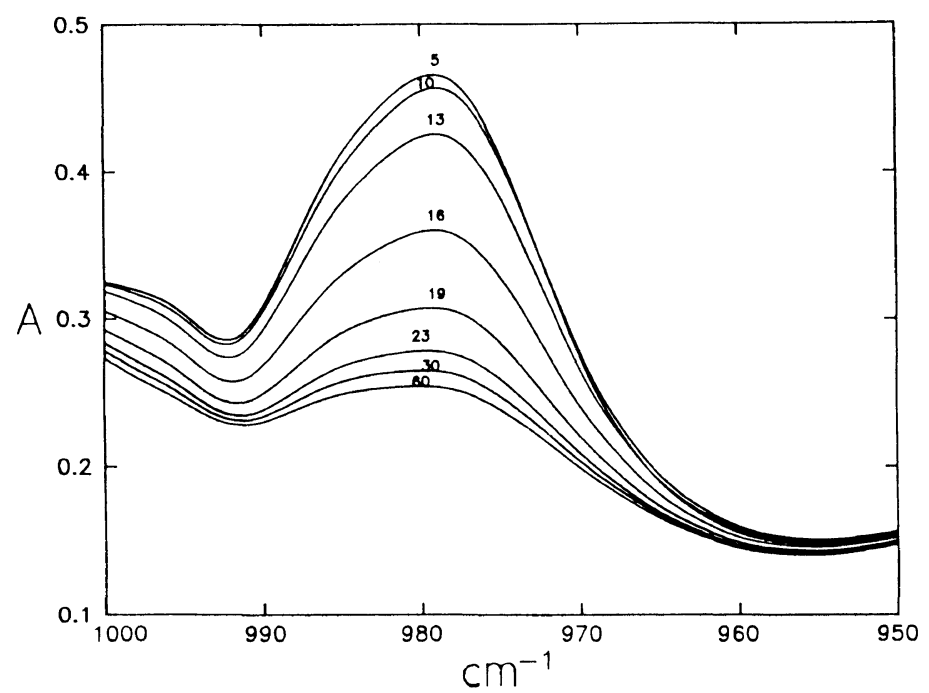

Figure 5. FTIR absorption spectra at $982 \mathrm{~cm}^{-1}$ of the unsaturated polyester with a styrene content of $33 \%$ cured at a temperature of $110^{\circ} \mathrm{C}$. The numeric values in the graph is the curing time.

In the use of DSC for studying the isothermal curing kinetics of thermosetting resins, one assumes that the amount of heat generated due to the curing reaction is directly proportional to the degree of cure (or the extent of reaction) of the sample at that time and then one relates the rate of cure, $\mathrm{d} \alpha / \mathrm{d} t$, to the rate of heat generated, $\mathrm{d} Q / \mathrm{d} t$, by:

$$
\frac{\mathrm{d} \alpha}{\mathrm{d} t}=\frac{1}{Q_{\mathrm{tot}}}\left(\frac{\mathrm{d} Q}{\mathrm{~d} t}\right)_{T}
$$

The subscript " $T$ " refers to isothermal curing reaction. Integrating eq 15 with respect to time, one obtains the degree of conversion, $\alpha$, 
The Curing Behavior of Unsaturated Polyester Resin

Table II. FTIR curing data of unsaturated polyester at $110^{\circ} \mathrm{C}$ (initial styrene content of the uncured resin is $33 \%$ )

\begin{tabular}{cccccc}
\hline Curing time & $\begin{array}{c}\text { Conversion/ } \\
\%\end{array}$ & $\begin{array}{c}\text { Residual } \\
\text { styrene } / \%\end{array}$ & $\begin{array}{c}\text { Crosslink density/ } \\
\%\end{array}$ & $T_{\mathrm{g}} / \mathrm{K}$ & $V_{\mathrm{f}}$ \\
\hline min & & & & & \\
\hline 0 & 0.0 & 32.9 & 0.0 & 252.4 & 0.0835 \\
5 & 0.0 & 32.9 & 0.0 & 252.4 & 0.0828 \\
8 & 2.15 & 32.0 & 0.24 & 255.2 & 0.0816 \\
10 & 5.24 & 30.9 & 0.84 & 259.3 & 0.0789 \\
13 & 15.2 & 27.7 & 3.17 & 273.2 & 0.0704 \\
16 & 37.6 & 20.5 & 8.29 & 308.2 & 0.0524 \\
17 & 45.3 & 18.0 & 9.95 & 321.5 & 0.0366 \\
19 & 56.2 & 14.3 & 12.25 & 341.4 & 0.0337 \\
21 & 63.5 & 11.6 & 13.63 & 355.5 & 0.0308 \\
23 & 67.8 & 10.2 & 14.57 & 369.2 & 0.0292 \\
25 & 70.5 & 9.2 & 15.02 & 376.8 & 0.0269 \\
30 & 74.2 & 7.7 & 15.52 & 380.7 & 0.0257 \\
35 & 76.1 & 6.9 & 15.82 & 383.8 & 0.0250 \\
41 & 77.6 & 6.3 & 16.02 & 385.2 & 0.0250 \\
45 & 78.3 & 5.9 & 16.1 & 387.1 & 0.0250 \\
50 & 79.2 & 5.6 & 16.3 & & \\
\hline
\end{tabular}

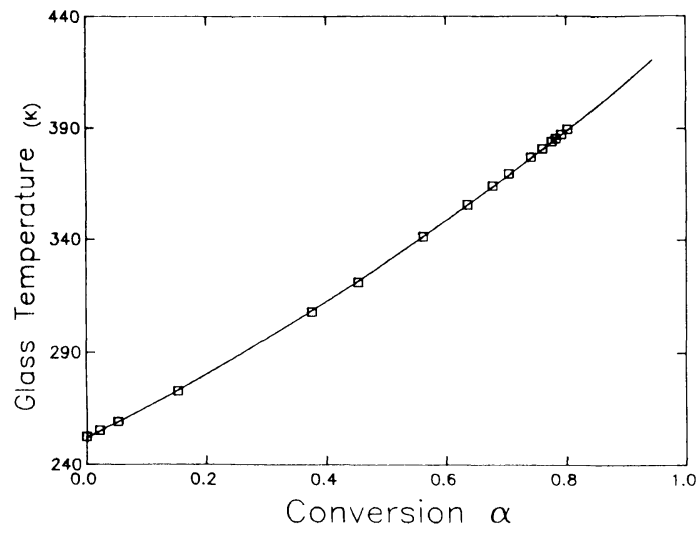

Figure 6. Glass transition temperature $\left(T_{\mathrm{g}}\right) v s$. conversion $(\alpha)$ together with the curve fitted to eq 14 .

$$
\alpha=\frac{1}{Q_{\mathrm{tot}}} \int_{t_{\mathrm{i}}}^{t}\left(\frac{\mathrm{d} Q}{\mathrm{~d} t}\right)_{T} \mathrm{~d} t
$$

where $Q_{\mathrm{tot}}=Q_{\mathrm{T}}+Q_{\mathrm{R}}, Q_{\mathrm{T}}$ is the heat generated during isothermal DSC runs and $Q_{\mathrm{R}}$ is the residual heat released when the sample was heated to $200^{\circ} \mathrm{C}$ on completion of an isothermal curing reaction, at the rate of $5^{\circ} \mathrm{C} \mathrm{min}^{-1}$. The isothermal DSC curing curves $\mathrm{d} \alpha / \mathrm{d} t v s$. curing time at temperatures $100^{\circ} \mathrm{C}$,

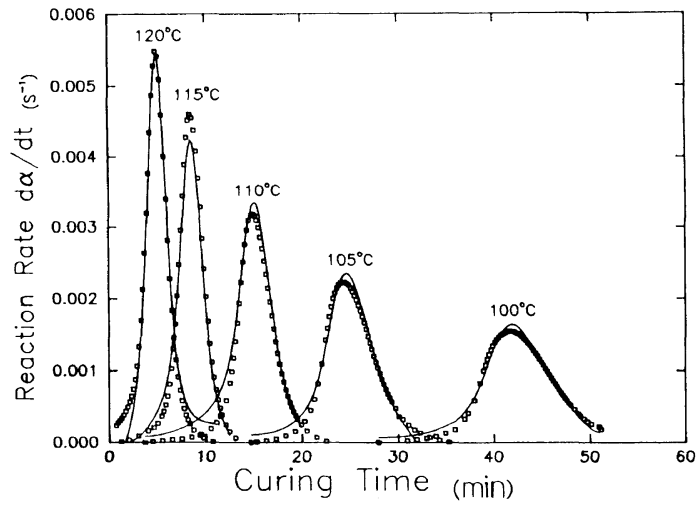

Figure 7. DSC isothermal curing data together with simulation curves. The curing temperatures are $100^{\circ} \mathrm{C}$, $105^{\circ} \mathrm{C}, 110^{\circ} \mathrm{C}, 115^{\circ} \mathrm{C}$, and $120^{\circ} \mathrm{C}$. ( $\square$ ), experimental data; (一), simulation curve with $\pi_{2}$ calculated from eq 22 .

$105^{\circ} \mathrm{C}, 115^{\circ} \mathrm{C}$, and $120^{\circ} \mathrm{C}$ are plotted in Figure 7 with square symbols. Plots of $\alpha$, vs. curing time are shown in Figure 8. Since we are not able to obtain the crosslinked density, and residual styrene monomer content etc. from DSC curing curves, the variation of $T_{\mathrm{g}}$ during the curing reaction can not be calculated from eq 3 . We used eq 14 to calculate the variation of $T_{\mathrm{g}}$ for the isothermal DSC curing reaction. 


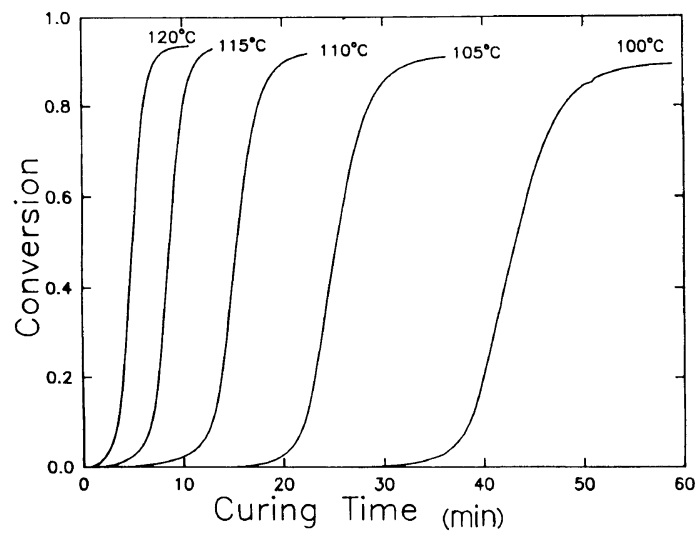

Figure 8. Conversion $\alpha$ calculated from DSC curing rate data vs. curing time. The curing temperatures are $100^{\circ} \mathrm{C}$, $105^{\circ} \mathrm{C}, 110^{\circ} \mathrm{C}, 115^{\circ} \mathrm{C}$, and $120^{\circ} \mathrm{C}$.

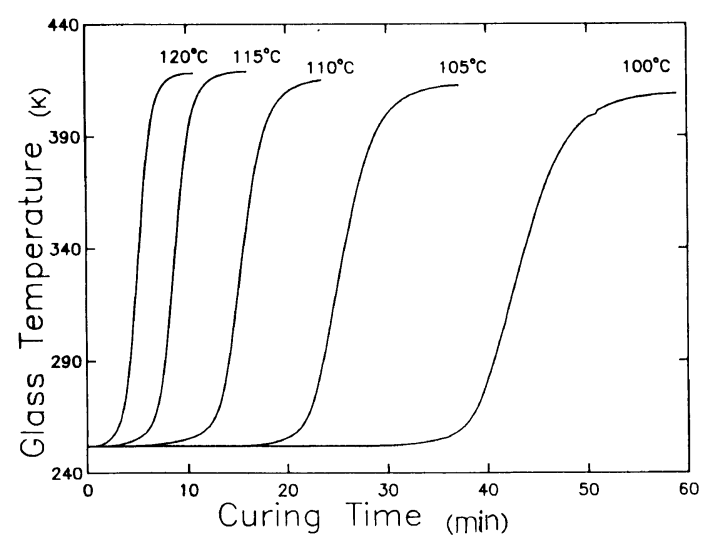

Figure 9. Variation of $T_{\mathrm{g}} v s$. curing time. The curing temperatures are $100^{\circ} \mathrm{C}, 105^{\circ} \mathrm{C}, 110^{\circ} \mathrm{C}, 115^{\circ} \mathrm{C}$, and $120^{\circ} \mathrm{C}$.

Equation 14 was derived from FTIR conversion data. The variation of $T_{\mathrm{g}} v s$. DSC curing time at $100^{\circ} \mathrm{C}, 105^{\circ} \mathrm{C}, 115^{\circ} \mathrm{C}$, and $120^{\circ} \mathrm{C}$ is plotted in Figure 9. The corresponding free volume fraction $v s$. curing time calculated from $T_{\mathrm{g}}$ by using eq 4 and 5 are also plotted in Figure 10.

\section{Curing Kinetics}

The dissociation constant of tert-butyl peroxybenzoate initiator can be obtained from the following equation:

$$
k_{\mathrm{d}}=A_{1} \exp (-E / R T)
$$

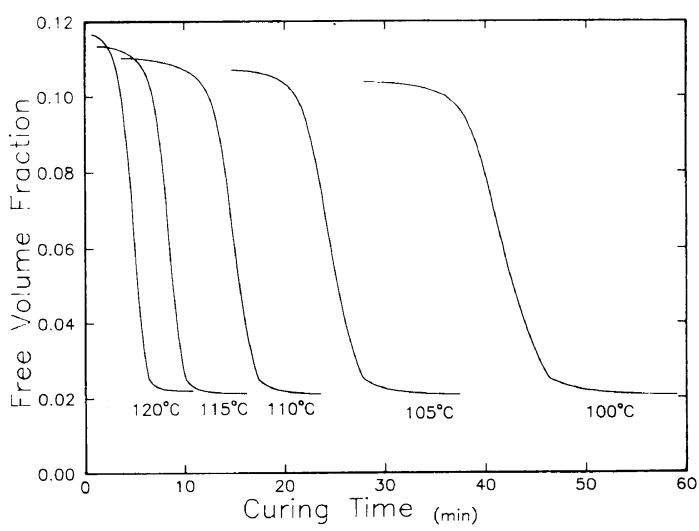

Figure 10. Free volume fraction $V_{\mathrm{f}}$ calculated from $T_{\mathrm{g}}$ $v s$. curing time. The curing temperatures are $100^{\circ} \mathrm{C}, 105^{\circ} \mathrm{C}$, $110^{\circ} \mathrm{C}, 115^{\circ} \mathrm{C}$, and $120^{\circ} \mathrm{C}$.

where $A_{1}=5.55 \times 10^{15} \mathrm{~min}^{-1}, E=1.34 \times 10^{5} \mathrm{~J}$ $\mathrm{mol}^{-1}$, and $R=8.314 \mathrm{~J} \mathrm{~mol}^{-1} \mathrm{~K}^{-1}$. The data of the constants $A_{1}$ and $E$ were obtained from the Akzo Chemie Co. ${ }^{21}$

From eq 8, 9, and 11, we obtain:

$$
\pi_{2} \pi_{3}=F f I_{0} k_{\mathrm{p} 0}\left[1-\exp \left\{-\left[k_{\mathrm{d}}\left(t-t_{\mathrm{z}}\right)\right]\right\}\right]
$$

By substituting eq 10 and 18 into eq 7 , we obtain:

$$
\begin{gathered}
\frac{1-\alpha}{\mathrm{d} \alpha / \mathrm{d} t}\left[1-\exp \left\{-\left[k_{\mathrm{d}}\left(t-t_{\mathrm{Z}}\right)\right\}\right]\right. \\
=\frac{1}{2 F f I_{0} k_{\mathrm{p} 0}}+A_{\mathrm{M}}\left[\exp \left(\frac{B_{\mathrm{M}}}{V_{\mathrm{f}}}\right)\right. \\
\left.\quad \times\left(1-\exp \left\{-k_{\mathrm{d}}\left(t-t_{\mathrm{Z}}\right)\right\}\right)\right]
\end{gathered}
$$

$F$ is usually found to be constant at the later stage of reaction $(F=1)$. From the later stage of reaction (the totally diffusion-controlled region for both free radical chains and monomers), $\pi_{3}$ and $\pi_{4}$ can be evaluated. Taking the later stage of DSC data, by varying the constant $B_{\mathrm{M}}$ and plotting the left hand side of eq 19 vs. $1-\exp \left\{-k_{\mathrm{d}}\left(t-t_{\mathrm{Z}}\right)\right\} \exp \left(B_{\mathrm{M}} / V_{\mathrm{f}}\right)$, the slope equals $A_{\mathrm{M}}$ and the intercept equals $1 / 2 F f I_{0} k_{\mathrm{p} 0}$. In this work, we obtained the best fit of 19 , by assuminging $B_{\mathbf{M}}=0.09$. In eq 19 , the value of $V_{\mathrm{f}}$ was calculated from eq 14,4 , 


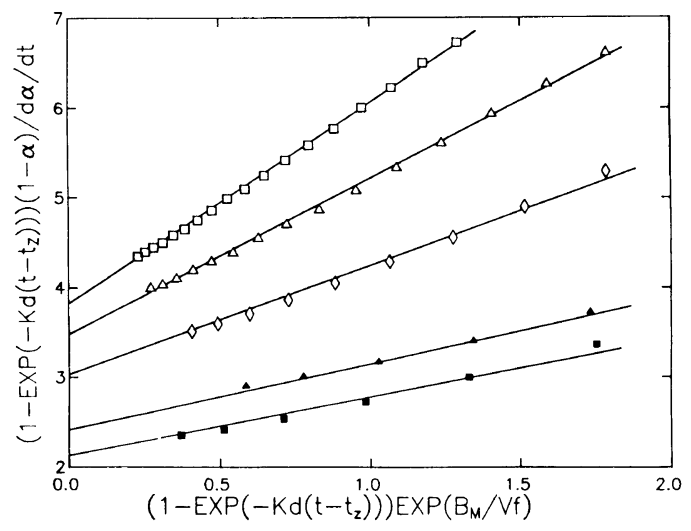

Figure 11. Plot of the left hand side of eq $19 v s$. $\left\{1-\exp \left[-k_{\mathrm{d}}\left(t-t_{\mathrm{z}}\right)\right]\right\} \exp \left(B_{\mathrm{M}} / V_{\mathrm{f}}\right) . \quad(\square), \quad 100^{\circ} \mathrm{C} ; \quad(\triangle)$, $105^{\circ} \mathrm{C} ;(\diamond), 110^{\circ} \mathrm{C} ;(\boldsymbol{\Delta}), 115^{\circ} \mathrm{C} ;(\square) 120^{\circ} \mathrm{C}$.

and 5. Figure 11 is the plot of eq 19 for unsaturated polyester resin cured at temperatures $100^{\circ} \mathrm{C}, 105^{\circ} \mathrm{C}, 110^{\circ} \mathrm{C}, 115^{\circ} \mathrm{C}$, and $120^{\circ} \mathrm{C}$. Using the data extracted from Figure 11, eq 20 and 21 for the variations of $A_{\mathrm{M}}$ and $F f I_{0} k_{\mathrm{p} 0}$ with temperature were obtained as,

$$
\begin{gathered}
A_{\mathrm{M}}(\mathrm{s})=7.308 \times 10^{-14} \exp (11606 / T) \quad(20) \\
F f I_{0} k_{\mathrm{p} 0}\left(\mathrm{~s}^{-1}\right)=1.234 \times 10^{4} \exp (-4.285 .7 / T)
\end{gathered}
$$

Substituting eq 20 for $A_{\mathrm{M}}$ and eq 14,4 , and 5 for $V_{\mathrm{f}}$ into eq $10, \pi_{4}$ can be obtained. Substituting eq 17 and 21 into eq $9, \pi_{3}$ can be obtained.

In their work, Huang et al..$^{17,22}$ estimated $\pi_{2}$ by fitting whole the reaction curve to the following empirical equation: $\ln \left(A_{\mathrm{p}} / F\right)=a+$ $b \ln \left(1 / V_{\mathrm{f}}\right)+c\left[\ln \left(1 / V_{\mathrm{f}}\right)\right]^{2}$, where $a, b$, and $c$ are three polynomial coefficients to be estimated. In the present work, $\pi_{2}$ was evaluated by fitting the whole reaction curve to eq 22 which is similar to the equation used by Huang et al.

$$
\pi_{2}=\frac{A_{\mathrm{p}}}{F} \exp \left(\frac{B_{\mathrm{p}}}{V_{\mathrm{f}}}\right)=A+\frac{B}{V_{\mathrm{f}}}+\frac{C}{V_{\mathrm{f}}^{2}}+\frac{D}{V_{\mathrm{f}}^{3}}
$$

where $A, B, C$, and $D$ are parameters to be estimated. Figure 12 is the plot of the left hand

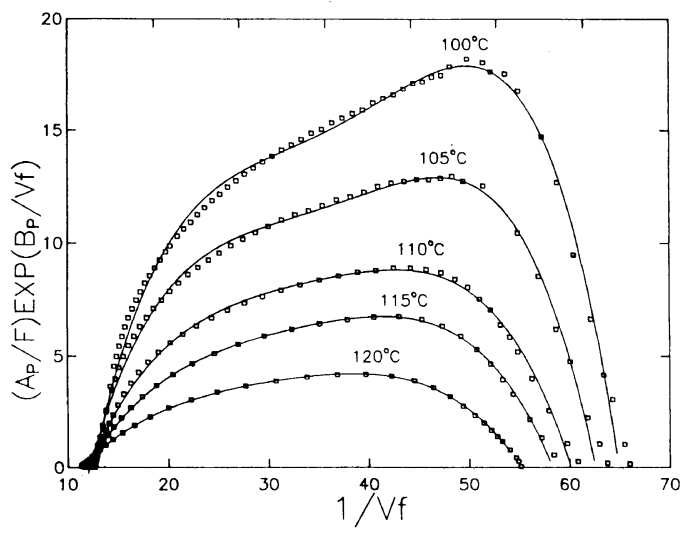

Figure 12. Plot of the left hand side of eq $22 v s .1 / V_{\mathrm{f}}$.

side of eq 22 vs. $V_{\mathrm{f}}$ for unsaturated polymer, the constants $A, B, C$, and $D$ with temperature are obtained:

$$
\begin{aligned}
& A=5.370 \times 10^{-16} \exp (14681 / T) \\
& B=4.155 \times 10^{-17} \exp (14901 / T) \\
& C=1.725 \times 10^{-19} \exp (15781 / T) \\
& D=3.100 \times 10^{-21} \exp (15815 / T)
\end{aligned}
$$

Substituting $\pi_{2}, \pi_{3}$, and $\pi_{4}$ into eq 7 , the values of $\mathrm{d} \alpha / \mathrm{d} t v s$. curing time can be obtained. The simulation curves for unsaturated polyester cured at $100^{\circ} \mathrm{C}, 105^{\circ} \mathrm{C}, 110^{\circ} \mathrm{C}, 115^{\circ} \mathrm{C}$, and $120^{\circ} \mathrm{C}$ are shown in Figure 7 together with DSC experimental data. Good agreement between the experimental results and the simulation curves was found.

However, $\pi_{2}$ can also be estimated from eq 28 which is obtained by substituting eq 11 into eq 8 .

$$
\pi_{2}=\frac{1}{k_{\mathrm{d}}}\left\{\exp \left[k_{\mathrm{d}}\left(t-t_{\mathrm{Z}}\right)\right]-1\right\}
$$

Substituting the $\pi_{2}$ values estimated from eq 28 together with $\pi_{3}$, and $\pi_{4}$ into eq 7 , the values of $\mathrm{d} \alpha / \mathrm{d} t v s$. curing time are shown in Figure 13 with dashed curves. From Figure 13, we found that the reaction rate of the simulation data is much fast than the DSC experimental data. Huang et al. assume that the termination 


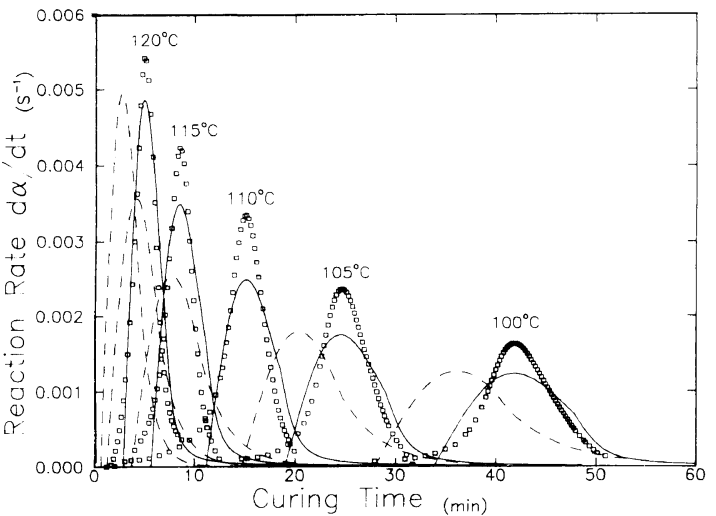

Figure 13. DSC isothermal curing data together with simulation curves. The curing temperatures are $100^{\circ} \mathrm{C}$, $105^{\circ} \mathrm{C}, 110^{\circ} \mathrm{C}, 115^{\circ} \mathrm{C}$, and $120^{\circ} \mathrm{C}$. ( $\square$ ), experimental data; (----), simulation curves with $\pi_{2}$ calculated from eq 28 ; (-), simulation curves with $\pi_{2}$ calculated from eq 29 .

of the curing reaction of unsaturated polyester is totally diffusion controlled in the whole period of the reaction. The reason for deviation between the simulation and the experimental data may be due to negligence of the kinetic effect on termination in the initial period of the curing reaction of the model eq 7 . Thus, if $\pi_{2}$ is calculated from eq 29 in which the induction time $t_{\mathrm{Z}}$ of eq 28 is substituted by gel time $t_{\text {gel }}$, better agreement between the simulation and experimental results is found. The simulation curves obtained by using $\pi_{2}$ calculated from eq 29 are also shown with full lines in Figure 13.

$$
\pi_{2}=\frac{1}{k_{\mathrm{d}}}\left\{\exp \left[k_{\mathrm{d}}\left(t-t_{\mathrm{gel}}\right)\right]-1\right\}
$$

\section{CONCLUSIONS}

In most cases, one may obtain residual styrene monomer and unreacted residual ester double bonds in the cured polyester network. Because of the additional cure reactions immediate after the glass transition, the glass transition temperature of the partially cured unsaturated polyester cannot be obtained by DSC. In this work, we demonstrated that TMA is a good means to determine the glass transition temperature of thermosetting poly- mers. A theoretical equation of $T_{\mathrm{g}}$ for crosslinked unsaturated polyester based on DiBenedetto's theory and the experimental results of TMA and FTIR was developed. The free volume during the period of the curing reaction calculated from $T_{\mathrm{g}}$ by using SimhaBoyer's free volume equation was applied to Huang's curing kinetic model. In our present work, we show that the simulation curves with $\pi_{2}$ calculated from eq 29 rather than eq 28 have better agreement with the experimental results. The reason for this may be that the termination of the curing reaction is not totally diffusion controlled and the kinetic effect on the termination in the initial period of the curing reaction is neglected in the model eq 7 .

Acknowledgment. The authors would like to acknowledge research support by the National Science Foundation of ROC through grant NSC-82-0405-E-155-015.

\section{REFERENCES}

1. K. W. Lem and C. D. Han, Polym. Eng. Sci., 24, 175 (1984).

2. S. W. Shalaby and H. E. Bair, Thermal Characterization of Polymeric Materials, E. A. Turi, Ed., Academic Press, New York, 1981.

3. J. D. Ferry, "Viscoelastic Properties of Polymers," John Wiley \& Sons, New York, 1980, Chapter 1.

4. L. E. Nielson, J. Macromol. Sci. Rev. Macromol. Chem., C3(1), 69 (1969).

5. H. Stutz, K.-H. Illers, and J. Mertes, J. Polym. Sci., Polym. Phys. Ed., 28, 1483 (1990).

6. S. C. Ma and T. L. Yu, J. Polym. Eng., to appear.

7. (a) R. Simha and R. F. Boyer, J. Chem. Phys., 37, 1003 (1962).

(b) R. F. Boyer and R. Simha, J. Polym. Sci., Polym. Lett. Ed., 11, 33 (1973).

8. M. R. Kamal, S. Slurour, and M. Ryan, SPE ANTEC Tech. Papers, 19, 187 (1973).

9. S. Y. Pusatcioglu, A. L. Fricke, and J. C. Hassler, J. Appl. Polym. Sci., 24, 937 (1979).

10. L. J. Lee and C. W. Macosko, Int. J. Heat Mass Transfer, 23(1), 479 (1980).

11. M. R. Barone and D. A. Caulk, Int. J. Heat Mass Transfer, 22, 1021 (1979).

12. J. N. Cardenas and K. F. O'Driscoll, J. Polym. Sci., Polym. Chem. Ed., 14, 883 (1976).

13. J. N. Cardenas and K. F. O'Driscoll, J. Polym. Sci., 
Polym. Chem. Ed., 15, 883 (1977).

14. J. N. Cardenas and K. F. O'Driscoll, J. Polym. Sci., Polym. Chem. Ed., 15, 2097 (1977).

15. F. L. Marten and A. E. Hamielec, ACS Symp. Ser. No. 104, 43 (1979).

16. W. Y. Chiu, G. M. Carratt, and D. S. Soong, Macromolecules, 16, 348 (1983).

17. Y. J. Huang and L. J. Lee, AIChE J., 31(10), 1585 (1985).

18. J. F. Stevenson, paper presented at the 1st
International Conference on Reactive Processing of Polymer, Pittsburgh. Oct., 1980.

19. L. J. Lee, Polym. Eng. Sci., 21, 483 (1981).

20. D. W. Van Krevelen and P. J. Hoftyzer, "Properties of Polymers," 2nd ed, Elsevier Science, Publishers, Co., 1976.

21. Akzo Chemie Co., Technical Data Sheet, Product Catalog, Deventer, the Netherlands (1986).

22. Y. J. Huang, J. D. Fan, and L. J. Lee, Polym. Eng. Sci., 30, 684 (1990). 